Research Article

Araştırma Makalesi

DOI: $10.24011 /$ barofd.854506
Bartın Orman Fakültesi Dergisi, 23 (1): 85-94,

15 Nisan/April, 2021
Journal of Bartin Faculty of Forestry

p-ISSN :1302-0943

e-ISSN :1308-5875

\title{
Burdur Kenti Parklarının Kullanımı Üzerine Bir Araştırma
}

\author{
Cengiz YÜCEDAĞ ${ }^{1}$, Latif Gürkan KAYA ${ }^{1 *}$, Mazlum EROL ${ }^{1}$ \\ ${ }^{1}$ Burdur Mehmet Akif Ersoy Üniversitesi, Mühendislik Mimarlık Fakültesi, Peyzaj Mimarlı̆̆ı Bölümü, 15030, \\ Burdur
}

\section{Öz}

Yeşil alanlar sadece kent insanının doğaya olan özlemini gidermekle kalmaz, aynı zamanda kentsel yaşamın olumsuz yönlerini de iyileştirmektedir. Bu anlamda, yeşil alanlardan parkların kullanımının detaylı bir şekilde incelenmesi büyük önem taşımaktadır. Bu çalışmanın amaçları, Burdur halkının kentte yer alan parkları kullanım durumlarını ortaya koymak, Burdur halkının parkların yeterlilikleri konusundaki görüşlerini ve parklar konusundaki beklentilerini belirlemektir. Bu amaçla, anket yöntemi kullanılmıştır. Katılımcıların çoğu parkları yaz mevsiminde arkadaşıyla ziyaret ettiklerini, parklara yürüyerek ulaştıklarını ve parkta 1-2 saat zaman harcadıklarını belirtmişlerdir. Cumhuriyet Parkı katılımcılar tarafindan en çok ziyaret edilen ve en çok beğenilen park olmuştur. Katılımcıların \%65'i Burdur kentinde bulunan park sayısını yeterli bulmuştur. Katılımcılar mahallelerindeki parklarda bisiklet parkı, çocuk oyun alanı, futbol sahası, çay ocağı, yürüyüş parkuru, spor aletleri, çeşme gibi eksikliklerin olduğunu ifade etmişlerdir. Kent insanının mahalle parklarından yeterince tatmin olmadığı sonucuna ulaşılmıştır. Bu husus, ilgili kurumlar tarafindan detaylı şekilde ele alınmalı ve söz konusu tatminsizliğin giderilmesi için çalışmalara hız verilmelidir.

Anahtar Kelimeler: Burdur, park kullanımı, yeşil alan, yeterlilik.

\section{A Research on Utilization of Parks in Burdur City, Turkey}

\begin{abstract}
Green lands not only satisfy urban people's longing for nature, but also amend the negative aspects of urban life. In this sense, it is of great importance that the utilization of parks by urban people, which are one of the green lands, are examined in detail. The aims of this study are to reveal the utilization of the parks by the people of Burdur, and to determine the views of people in Burdur about the adequacy of the parks and their expectations about the parks. For this purpose, the survey method was used. Most of the participants stated that they visited the parks with their friends during the summer season, reached the parks on foot and spent 1-2 hours in the park. Cumhuriyet Park was the most visited and liked park by the participants. 65\% of the participants found the number of parks in Burdur enough. Participants indicated that there are deficiencies in the parks in their neighborhoods such as bicycle park, playground, football field, teahouse, walking trail, sports equipment and fountains. It was concluded that people in Burdur are not satisfied enough with the neighborhood parks. This issue should be elaborately addressed by the relevant institutions and efforts should be accelerated to eliminate the dissatisfaction in question.
\end{abstract}

Keywords: Burdur, park utilization, green land, competency. 


\section{Giriş}

Kırsal nüfusun kentlerde kontrolsüz yoğunlaşması, kentlerin plansız ve hızlı bir şekilde betonlaşması ile doğadan giderek uzaklaşan büyük yerleşimlere dönüşmesine neden olmaktadır. Doğadan uzaklaşan kentler, toplumda sosyal, ekonomik ve psikolojik sorunlar ortaya çıkarmaktadır. Kent insanları bu sorunların üstesinden gelmek için doğa temelli mekânlara ihtiyaç duymaktadır. Bu mekanlardan biri de hiç kuşkusuz kentte yer alan yeşil alanlardır. Yeşil alanlar sadece kent insanının doğaya olan özlemini gidermekle kalmaz, aynı zamanda kentsel yaşamın olumsuz yönlerini de iyileştirmektedir.

Yeşil alanlardan biri olan parkların görevleri kültürel ve kişisel farklılığın sergilenmesi, demokratik çeşitliğin ve görüş açılarının vurgulanması ile toplum içerisindeki iletişimin sağlanmasına yardımcı olmaktır (Özdemir, 2009; Zhu vd., 2020). Bu anlamda, özellikle yetersiz rekreasyon alanlarına sahip kentlerde parkların farklı kullanıcılara hitap etmesi beklenmektedir (Galecic vd., 2016). Nitekim, Mutiara ve Isami (2012) kent insanının çekici doğal alanlar yerine çeşitli rekreasyonel aktiviteleri içeren parkları tercih ettiklerini ve park planlamada sosyal ve ekolojik etmenlerin birlikte düşünülmesi gerektiğini ifade etmişlerdir. Park işletmecilerinin toplumun daha fazla faydalanmasını sağlayacak şekilde parkların değerini artırmaları gerekmektedir (Mutiara ve Isami, 2012). Bu nedenle, parkların kent insanı tarafından kullanımının detaylı bir şekilde incelenmesi büyük önem taşımaktadır. Böylece kent insanının parkı kullanım durumu ve parktan beklentileri dikkate alınarak parkın mevcut özellikleri iyileştirilebilecek ya da daha nitelikli yeni parkların tesisi mümkün olabilecektir. Bu konuda, Cohen vd. (2016) park kullanımının artmasında en önemli tahmin edici değişkenlerin parklarda düzenli ve kontrollü aktivitelerin varlığının olduğunu belirtmişlerdir. Nam ve Kim (2016) ise, park kullanımının parkı ziyaret amacı, ziyaret sıklığı ve parka ulaşım biçimine bağlı olarak farklılıklar gösterdiğini ve yine park planlamasında kapsamlı ve sistematik kriterlerin gerekli olduğunu vurgulamışlardır. Parkların planlamasında proaktif bir yaklaşımın izlenmesi ve mevcut arazinin en iyi şekilde nasıl kullanılacağının düşünülmesi gerekmektedir (Ellis ve Schwartz, 2016).

Bugüne kadar Türkiye'de; Ankara (Özdemir, 2009; Önal ve Sağır, 2018), Antalya (Yılmaz vd., 2014; Yılmaz vd., 2016a-b; Olgun vd., 2018; Kaya vd., 2019; Soydan vd., 2019), Aydın (Kasap ve Kara, 2020), Artvin, Rize ve Trabzon (Sarı, 2019), Bartın (Gökyer ve Bilgili, 2014), Eskişehir (Gürbüz ve Yılmaz, 2017), İstanbul (Kutay Karaçor ve Çıracı, 2016; Şenkaya vd., 2019), Konya (Polat, 2012), Niğde (Olgun ve Yılmaz, 2014; Soydan, 2020), Samsun (Karadeniz, 2019; Kından ve Çiçek, 2020), Sivas (Erdoğan vd., 2020), Van (Bilgili vd., 2011) ve Yozgat (Yazici ve Temizel, 2020) kentlerindeki parklar kullanım yönünden incelenmiştir. Burdur kentinde parkların kullanımı üzerine bir çalışma olmamasına rağmen, Ulu Akşit vd. (2020) tarafından yürütülen bir araştırma, Burdur kentinde kişi başına $8,4 \mathrm{~m}^{2}$ açık-yeşil alan düştüğünü, kent mevcut açık-yeşil alanlarının gelişigüzel bir dağılıma sahip olduğunu, bu alanlardaki bitkilerin estetik ve işlevsel özellikleri açısından kent insanının ihtiyaçlarını karşılayacak nitelikte olmadığını, bitkisel tasarımın yetersiz olduğunu ve kullanılan bitki türlerinin mekanın kalitesini artırmada yeterli olmadığını ortaya koymuştur.

Yukarıda verilen bilgiler 1şı̆̆ında bu çalışmadaki amaçlar, (i) Burdur halkının kentte yer alan parkları kullanım durumlarını ortaya koymak, (ii) Burdur halkının parkların yeterlilikleri konusundaki görüşlerini ve (iii) parklar konusundaki beklentilerini belirlemektir.

\section{Materyal ve Metot}

Bu çalışmada Burdur kenti çalışma alanı olarak seçilmiştir (Şekil 1). 2019 yılı itibariyle Burdur merkez ilçe nüfusu 115159'dur (TÜİK, 2020). Burdur ili için 2014 yılı kentleşme oranı \%65,3’dür (Kiziroğlu, 2017). 

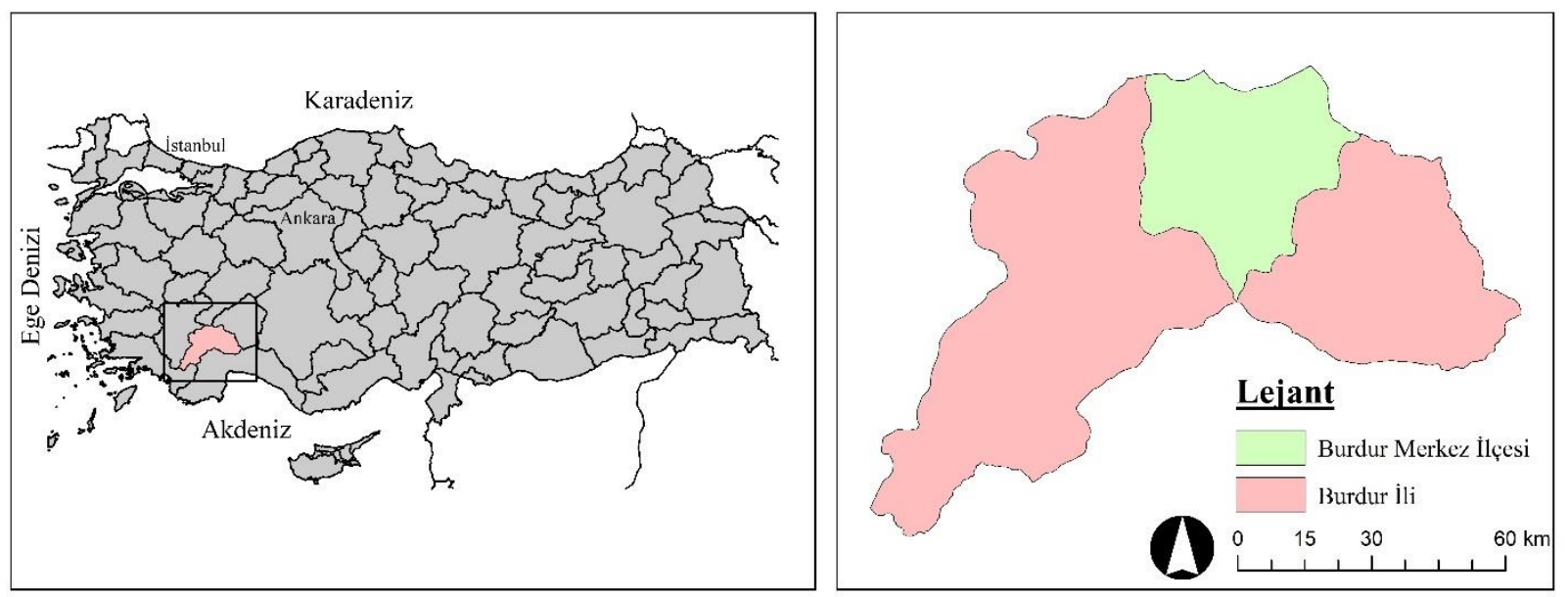

Şekil 1. Burdur kentinin genel konumu.

Burdur kent merkezinde bulunan 35 mahallede toplam 131 park bulunmaktadır (Şekil 2). Bu parklardan alan olarak en büyügü Burç Mahallesi'nde yer alan Cumhuriyet Parkı $\left(6838 \mathrm{~m}^{2}\right)$ ve en küçcügü ise İnönü Mahallesi'nde yer alan Yeni Hamam Karşısı Parkı'dır (59 m²) (Anonim, 2019).

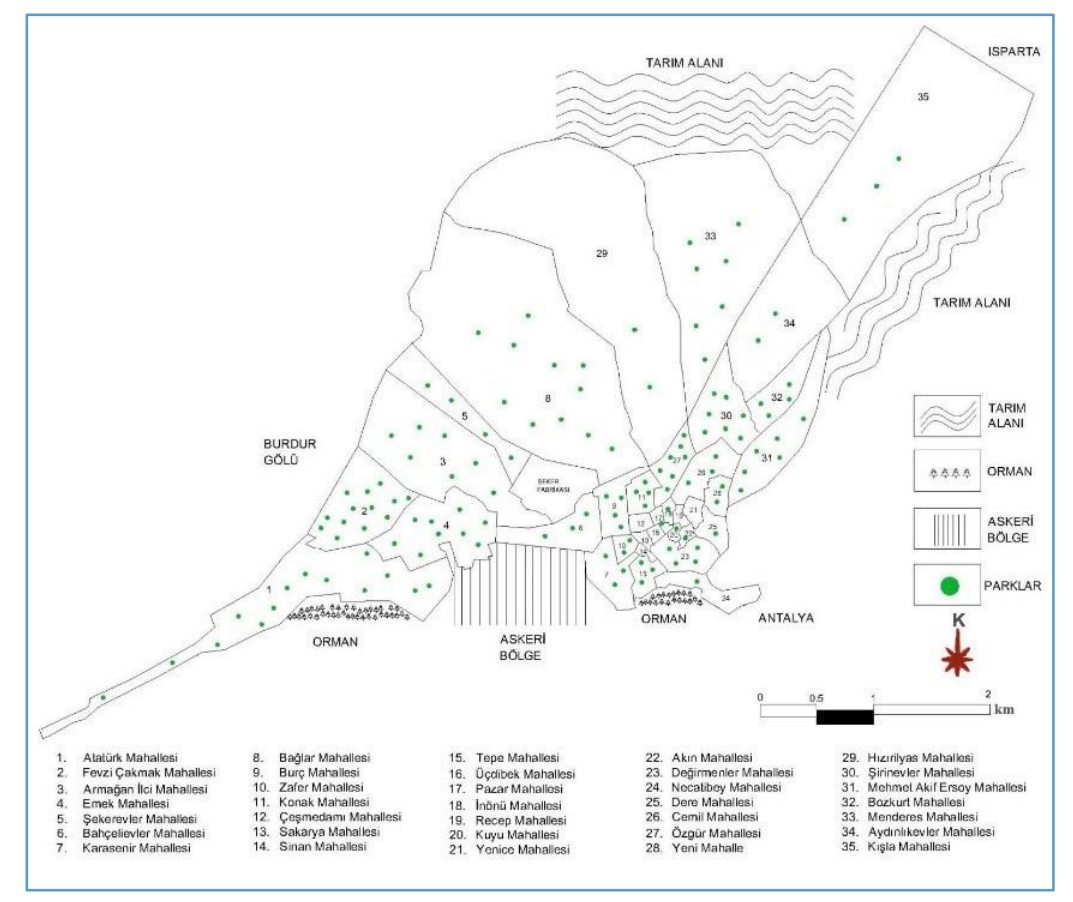

Şekil 2. Burdur kenti mahallelerinde bulunan parklar (Ulu Akşit vd., 2020).

Çalışmada veri toplama aracı olarak anket yöntemi kullanılmıştır. 2019 yılının Eylül-Ekim aylarında Burdur kentinin merkezi sayılan Cumhuriyet Meydanı ve İstasyon Caddesi civarında rastgele toplam 100 kişiye yüz yüze anket uygulaması gerçekleştirilmiştir. Örneklem büyüklüğünde, Yazıcıŏglu ve Erdoğan (2007) tarafindan $\pm 0,10$ örneklem hatası ve heterojen bir evren dağılımı ( $\mathrm{p}=0,50$ ve $\mathrm{q}=0,50)$ için hesaplanan değer (96) dikkate alınmış ama daha güvenilir sonuçlara ulaşabilmek amacıyla örneklem büyüklüğü 100 olarak kararlaştırılmıştır. Anket formu katılımcıların demografik özelliklerine ilişkin, parkları ziyaretlerine ilişkin, mahallelerindeki parkların bazı özellikler bakımından yeterliliklerine ilişkin, parklarda gördükleri eksikliklere ilişkin, en çok ziyaret ettikleri ve en beğendikleri parklara ilişkin sorulardan oluşmaktadır. Her katılımeı her bir soru için sadece bir seçenek işaretlemiştir. Katılımcıların 19 farklı mahallede ikamet ettikleri tespit edilmiştir (Tablo 1). 
Tablo 1. Katılımcıların ikamet mahalleleri (Toplam mahalle sayısı=19; $n=100$ ).

\begin{tabular}{llll}
\hline Mahalle Adı & $\begin{array}{l}\text { İkamet Eden } \\
\text { Katılımcı Sayısı }\end{array}$ & Mahalle Adı & $\begin{array}{l}\text { Íkamet Eden } \\
\text { Katılımcı Sayısı }\end{array}$ \\
\hline Zafer & 16 & Necati Bey & 4 \\
Bahçelievler & 15 & Mehmet Akif Ersoy & 3 \\
Fevzi Çakmak & 13 & Akın & 2 \\
Burç & 10 & Pazar & 2 \\
Emek & 6 & Kuyu & 2 \\
Konak & 5 & Kışla & 2 \\
Atatürk & 5 & Şekerevler & 1 \\
Aydınlık Evler & 4 & Recep & 1 \\
Şirinevler & 4 & Armağan İlci & 1 \\
Bağlar & 4 & & \\
\hline
\end{tabular}

Elde edilen verilere frekans ve varyans analizleri yapılmıştır. Bütün analizler SPSS istatistik programı ile gerçekleştirilmiştir. Frekans analizi sonuçları tablo ve grafikler halinde sunulmuştur.

\section{Bulgular ve Tartışma}

\subsection{Katılımcıların demografik özellikleri}

Katılımcılara ait demografik özellikler Tablo 2'de sunulmuştur. Buna göre, katılımcıların çoğunluğu erkek (66), öğrenci ve özel sektör çalışanı (65), 18-35 yaş grubu (68), bekar (62), lise ve lisans mezunu (63), çocuksuz (67) ve 2501-5000 TL aile gelir durumuna (50) sahiptir. Burdur'da ikamet sebebi olarak, 42 katılımcı doğup büyüdüğü yer, 36 katılımcı ise öğrencilik olduğunu belirtmiştir. 45 katılımc1 5 yıldan daha az ve 44 katılımc1 ise 10 yıldan daha uzun süre Burdur'da ikamet ettiğini bildirmiştir. Katılımcıların yaklaşık yarısı evinin kira (45), diğer kalan kısmı ise ev sahibi (55) olduğunu ifade etmiştir.

Tablo 2. Katılımcıların demografik özellikleri.

\begin{tabular}{|c|c|c|c|c|c|}
\hline Değişkenler & $\mathbf{f}$ & Değişkenler & f & Değişkenler & f \\
\hline Cinsiyet: & & Medeni Durumu: & & Aile Gelir Durumu: & \\
\hline Kadın & 34 & Bekar & 62 & $2500 \mathrm{TL}$ ve alt 1 & 24 \\
\hline \multirow[t]{3}{*}{ Erkek } & 66 & Evli & 38 & $2501-5000 \mathrm{TL}$ & 50 \\
\hline & & & & 5001-7500 TL & 17 \\
\hline & & & & 7501 TL ve üstü & 9 \\
\hline Meslek: & & Ĕ̈itim Dигити: & & Eviniz Kira mı: & \\
\hline Öğrenci & 39 & İlkokul & 12 & Kira & 45 \\
\hline Kamu çalışanı & 6 & Ortaokul & 8 & Ev sahibi & 55 \\
\hline Özel sektör & 26 & Lise & 22 & Burdur'da ikamet sebebiniz: & \\
\hline Emekli & 10 & Önlisans & 11 & Doğup büyüdüğüm yer & 42 \\
\hline Ev hanımı & 11 & Lisans & 41 & İş gereği & 13 \\
\hline Serbest meslek & 6 & Lisansüstü & 6 & Öğrencilik & 36 \\
\hline İşsiz & 2 & & & Evlilik & 9 \\
\hline Yaş: & & Çocuk Sayısı: & & Burdur'da ikamet süreniz: & \\
\hline $18-25$ & 48 & 0 & 67 & $<5 \mathrm{y} 1 \mathrm{l}$ & 45 \\
\hline $26-35$ & 20 & 1 & 5 & 5-10 y1l & 11 \\
\hline $36-45$ & 14 & 2 & 12 & $>10$ y1l & 44 \\
\hline $46-55$ & 6 & 3 ve üstü & 16 & & \\
\hline $56-65$ & 10 & & & & \\
\hline 66 ve üstü & 2 & & & & \\
\hline
\end{tabular}




\subsection{Katılımcıların Park Ziyaretlerine İlişkin Özellikler}

Katılımcıların çoğu parkları yaz mevsiminde (\%74) arkadaşıyla (\%58) saat 14:00-20:00 saatleri (\%66) arasında ziyaret ettiğini ve 1-2 saat (\%62) zaman harcadıklarını belirtmişlerdir (Tablo 3). Bu bulgulara paralel şekilde, Önal ve Sağır (2018) Ankara kent parklarının kullanımını inceledikleri çalışmalarında katılımcıların parkları çoğunlukla arkadaşlarıyla ziyaret ettiklerini ve parklarda 1-3 saat kaldıklarını işaret etmiştir. Gürbüz ve Yılmaz (2017) Eskişehir-Kentpark'ta ve Kaya vd. (2019) Antalya-Dokuma parkta katılımcıların daha çok 1-2 saat zaman geçirdiklerini bulmuşlardır. Bu bulgulara karşılık, Niğde (Soydan, 2020) ve Aydın’da (Kasap ve Kara, 2020) yürütülen benzer çalışmalarda katılımcıların parklara daha çok çocuklarla geldikleri ve 1 saatten az zaman geçirdikleri tespit etmiştir.

Katılımcılar parklara daha çok yürüyerek (\%73) ulaşım sağlamaktadırlar (Tablo 3). Benzer şekilde, DenizliPamukkale'de yer alan kent parkı (Yücedağ vd., 2018) ile Antalya-Dokuma parkının (Kaya vd., 2019) kente yürüme mesafesinde olmalarından dolayı katılımcılar tarafından daha çok yürüyerek ziyaret edildikleri bulunmuştur. Yine, bir parka kolay ulaşılabilirlik o parkı yüksek nitelikte bir park saymada etkin bir faktördür (Galecic vd., 2016). Ziyaret sıklığı bakımından katılımcılar arasında belirgin bir farklılık bulunmamaktadır (Tablo $3)$.

Tablo 3. Katılımcıların ziyaretlerine ilişkin özellikler.

\begin{tabular}{llll}
\hline Değişkenler & $\mathbf{f}$ & Değişkenler & f \\
\hline Ziyaret Siklı̆̆l: & 5 & Tercih edilen mevsim: & 0 \\
Hergün & 27 & Kiş & 25 \\
Haftada birkaç kez & 18 & İlkbahar & 74 \\
Haftada bir & 26 & Yaz & 1 \\
Ayda birkaç kez & 24 & Sonbahar & \\
Ayda bir & & & 10 \\
\hline Ziyaret saatleri: & 5 & Kimlerle gelmekte: & 9 \\
08:00-12:00 & 7 & Ailemle & 58 \\
12:00-14:00 & 27 & Çocuğumla & 23 \\
14:00-17:00 & 39 & Arkadaşımla & \\
17:00-20:00 & 22 & Yalnız & \\
20:00'den sonra & & & 15 \\
\hline Parkta harcanan süre: & 37 & Ulaşım: & 7 \\
$<1$ saat & 62 & Özel araç & 73 \\
1-2 saat & 1 & Toplu taşıma & 5 \\
Tam gün & & Yürüyerek & Bisikletle \\
& & & \\
\hline
\end{tabular}

Katılımcıların parkları arkadaşlarla zaman geçirmek (\%35) ve hava almak (\%27) amaçlarıyla daha çok ziyaret ettikleri, piknik (1) amacıyla daha az ziyaret ettikleri ortaya çıkmıştır (Şekil 3). Nitekim, Önal ve Sağır (2018), Kaya vd. (2019) ile Soydan ve ark. (2019) parkların öncelikli olarak ziyaret edilme amaçlarını doğada vakit geçirmek, dinlenmek ve arkadaşlarla buluşmak olarak tespit etmişlerdir. Kasap ve Kara (2020) tarafından AydınTataristan Bugulma Parkı'nın kullanımı üzerine yürütülen çalışmada katılımcıların parkı daha çok dinlenmek amaçlı tercih ettiği bulunmuştur. Bu bulgulara karşılık, Yücedağ vd. (2018) Denizli-Pamukkale ilçesinde yer alan kent parkını inceledikleri bir araştırmada, katılımcıların parkı birinci olarak yürüyüş, ikinci olarak da parkta bulunan spor aletlerini kullanmak amaçlarıyla ziyaret ettikleri belirtmişlerdir. Karadeniz (2019) Samsun kenti parklarını katılımcıların daha çok sosyal aktivite amacıyla ziyaret ettiğini bulmuştur. 


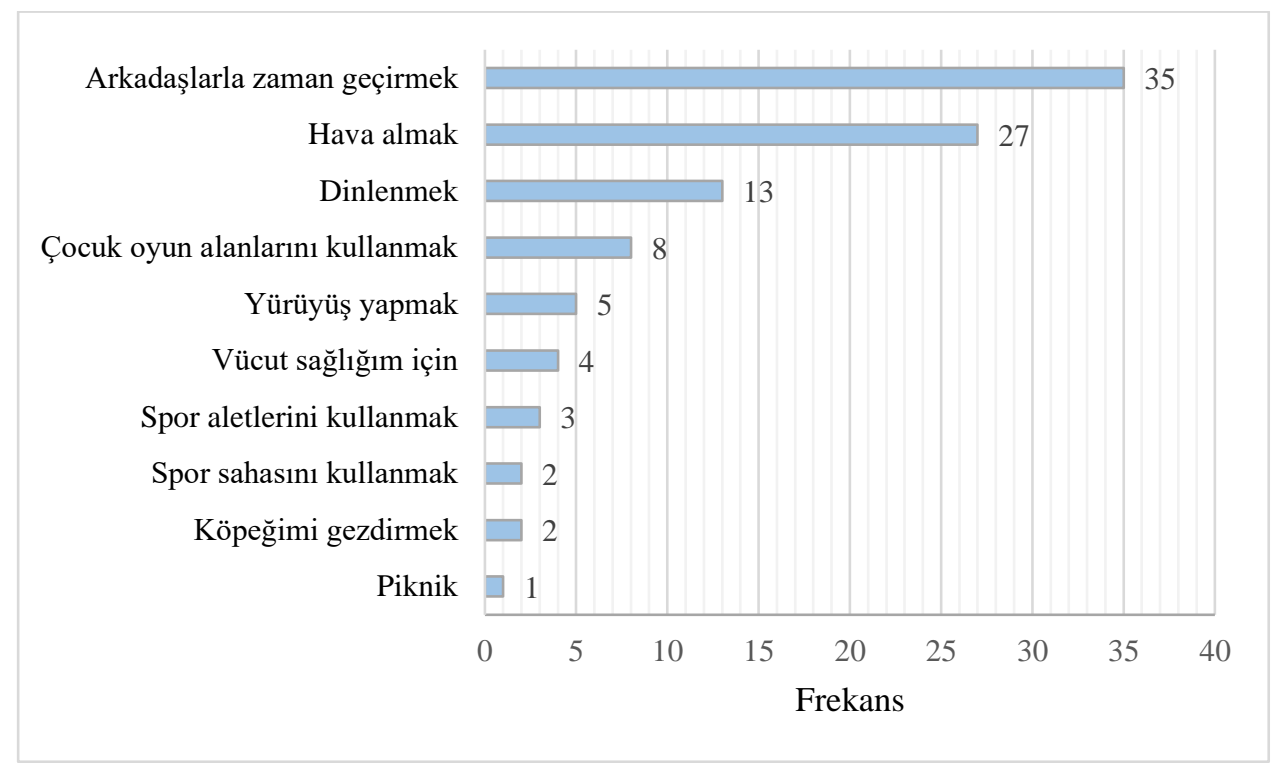

Şekil 3. Katılımcıların parkları ziyaret amaçları.

\subsection{Katılımcıların Burdur Kentinde En Çok Ziyaret Ettikleri ve En Çok Beğendikleri Parklar ile En Çok Ziyaret Edilen Parkları Ziyaret Sebepleri}

Cumhuriyet parkı katılımcılar tarafindan en çok ziyaret edilen (\%34) ve en çok beğenilen (\%46) park olmuştur. En çok ziyaret edilen park durumuna göre, İstasyon parkı (\%20) Gençlik parkına (\%14) kıyasla daha fazla ziyaret ediliyor olsa da, her iki park katılımcılar tarafından aynı oranda (\%17) en çok beğenilen parklar olarak işaretlenmişlerdir (Şekil 4). Cumhuriyet ve İstasyon Parklarının katılımcılar tarafından en çok ziyaret edilen parklar olarak seçilmesinin sebepleri yakınlarında kafe/restoran olması (\%20), yeterli yeşil dokuya sahip olmaları (\%18) ile aydınlatmalarının yeterli olmasıdır (\%8) (Șekil 5). Benzer șekilde, Kından ve Çiçek (2020) Samsun kentinde yer alan Batı Park'ın farklı spor aktivitelerinin yanısıra, lokanta ve çay bahçesi gibi alternatif park içi olanaklara da sahip olduğunu belirtmiştir. Semt, Ali Samiyen, Ekrem Kabay, Çocuk ve Mahalle Parkları katılımcılar tarafından ziyaret edilmelerine rağmen, hiçbiri en çok beğenilen park olarak seçilmemiştir. $\mathrm{Bu}$ parkların katılımcılar tarafından en çok ziyaret edilen parklar olarak gösterilmesinin ana sebebi konakladıkları yere yakın olmalarıdır (\%38) (Şekil 5). Gazi Park ise, en çok beğenilen park olarak seçilmesine rağmen, ziyaret edilen park olarak belirtilmemiştir (Şekil 4). Bu parkın en çok beğenilme sebebi katılımcıların konakladıkları yere yakın olması olabilir iken, hiç ziyaret edilmemesinin sebebi ise yeterli oturma elemanına sahip olmaması ve güvenli bulunmaması olabilir. Diğger taraftan, katılımcıların \%65'i Burdur kentinde bulunan park sayısını yeterli bulmuştur. Bu bulguya rağmen, Ulu Akşit vd. (2020) sadece parklarda bulunan yeşil alan dikkate alınarak parklarda kişi başına 1,6 $\mathrm{m}^{2}$ yeşil alan düştüğünü belirtmişlerdir.

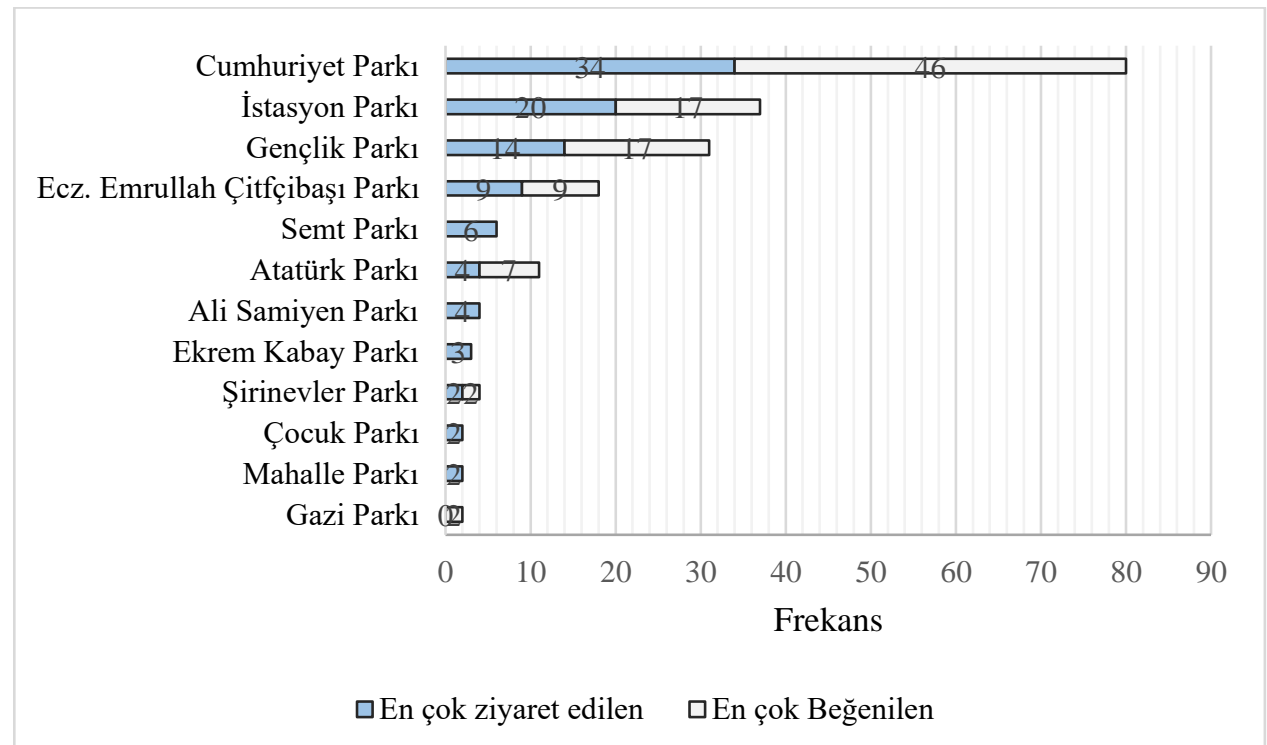

Şekil 4. Katılımcılar tarafindan Burdur kentinde en çok ziyaret edilen ve en çok beğenilen parklar. 


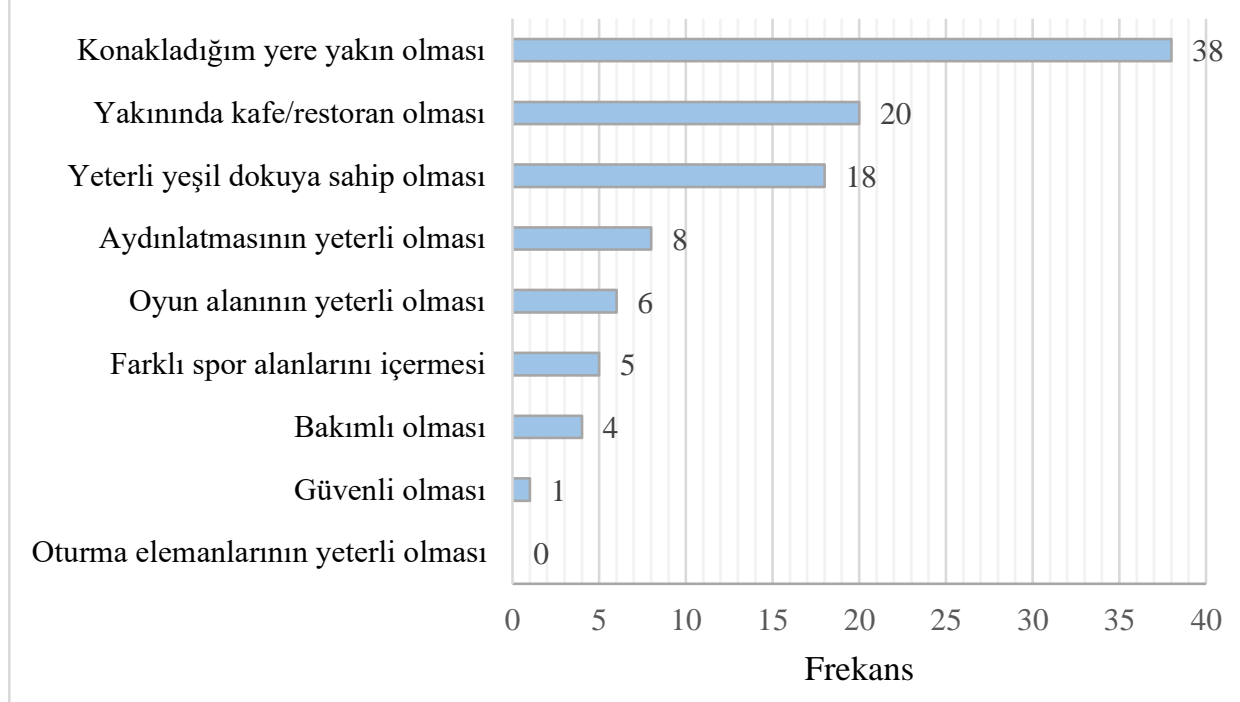

Şekil 5. Katılımcıların en çok ziyaret edilen parkları ziyaret sebepleri.

\subsection{Katılımcıların Mahallelerindeki Parkların Bazı Özellikler Bakımından Yeterlilikleri}

Katılımcılar mahallelerindeki parkların güvenlik, donatı elemanı, oyun alanı, bakım, spor alanı ve aydınlatma yeterliliklerini genel olarak orta düzeyde bulmaktadırlar (Şekil 6).

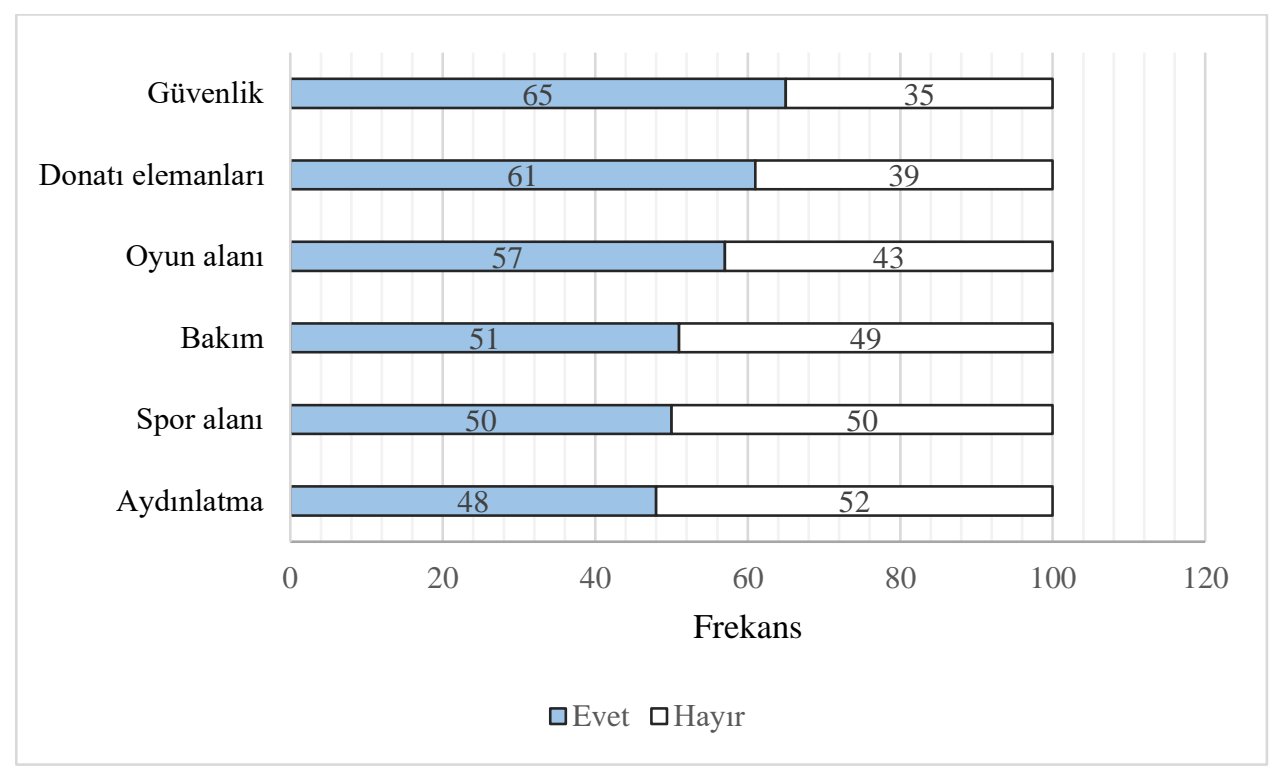

Şekil 6. Katılımcıların mahallelerindeki parkların bazı özellikler bakımından yeterlilikleri.

\subsection{Katılımcıların Mahallelerindeki Parklarında Gördükleri Eksiklikler}

Katılımcılar her ne kadar mahallelerindeki parkların bakım, güvenlik, aydınlatma ve oyun alanı yeterliliklerini orta düzeyde bulmuş olsa da, parklarında gördükleri eksiklikler sorusuna bu özellikleri ciddi eksiklikler olarak bildirmişlerdir (Şekil 7). Soydan (2020) tarafından yapılan çalışmada da, Niğde'de yer alan kent parklarının aydınlatmasının yeterli olmadığı bulunmuştur. Karadeniz (2019) Samsun kent parklarında güvenlik eksikliğinin olduğunu belirtmiştir. Bunların yanında, katılımcılar mahallelerindeki parklarda bisiklet parkı, sokak hayvanları için besleme kapları, yeşil doku, futbol sahası, çay ocağı ve çeşmeyi önemli eksiklikler olarak belirlemişlerdir (Şekil 7). Sarı (2019) tarafından Artvin, Rize ve Trabzon illerinin sahil kesimlerinde konumlanmış üç kent parkının incelendiği araştırmada, genel olarak tüm parklarda sosyalleşme, dinlenme, eğlenme, seyir, beslenme, oyun, spor, alışveriş ihtiyaçlarına yönelik olarak çeşitli mekanların tasarlanmış olduğu, yani bu kent parklarının ziyaretçilerin genel ihtiyaçlarını karşılayabildikleri ortaya konmuştur. Yine, İstanbul'da farklı sosyo-ekonomik 
yapıya sahip mahallelerden 4 mahalle parkında yürütülen bir çalışmada (Kutay Karaçor ve Çıracı, 2016), Sancaktepe ve Sultanbeyli parklarının ziyaretçileri parklarda uygun fiyatlı bir restoranın bulunmasını talep ettikleri bulunmuştur.

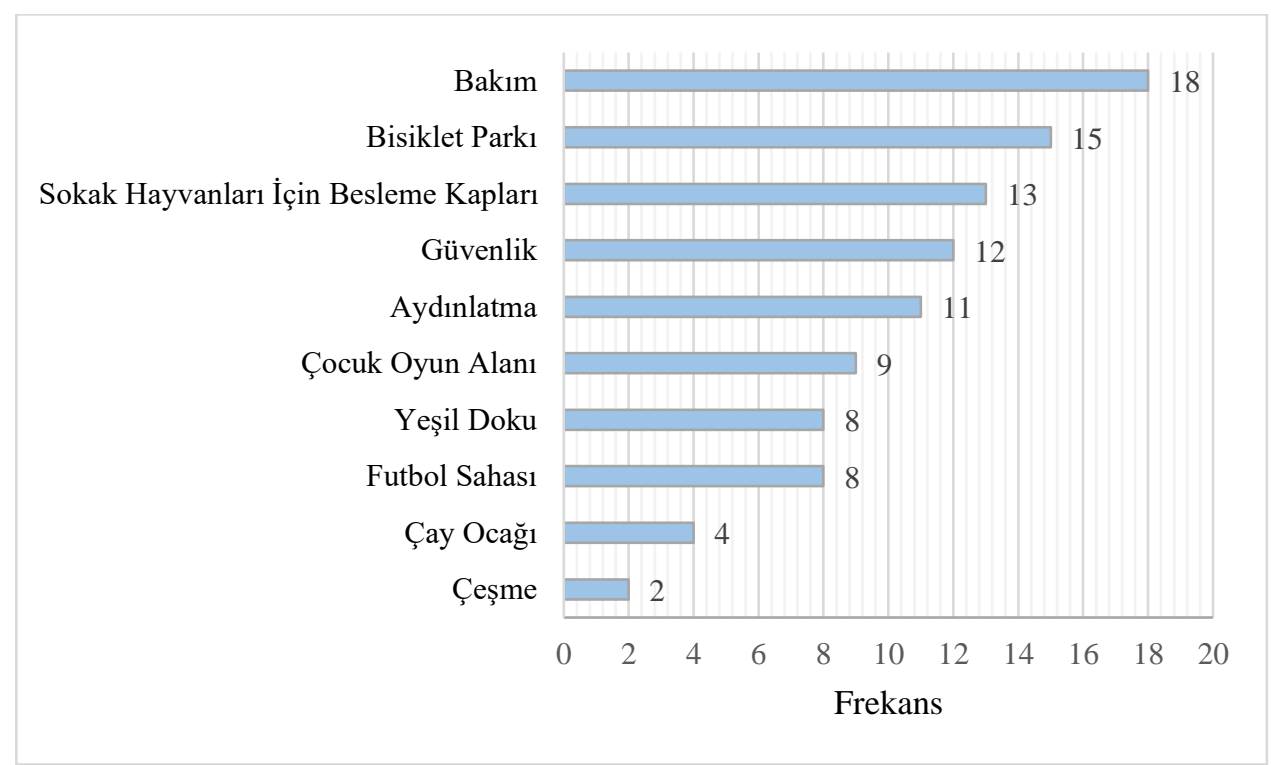

Şekil 7. Katılımcıların mahallelerindeki parklarda gördükleri eksiklikler.

\subsection{Katılımcıların Mahallelerindeki Parklarda Olmasını İstedikleri Donatılar}

Katılımcıların çoğunluğu mahallelerindeki parklarda oturma gruplarının (\%30), spor aletlerinin (\%18), aydınlatma armatürünün (\%12), çöp kutusunun (\%9) ve çocuk oyun alanının (\%8) olmasını istediklerini ifade etmişlerdir (Şekil 8). Nitekim, Ulu Akşit vd. (2020) Burdur kenti parklarının çoğunun küçük ve dinlenme, spor, oyun gibi aktivitelerin bir arada yer alması nedeniyle kendilerinden beklenen işlevleri yerine getiremediklerini ve bundan dolayı düşük peyzaj standardına sahip bu parkların yenilenerek estetik ve işlevsel değerler kazandırılması gerektiğini vurgulamışlardır.

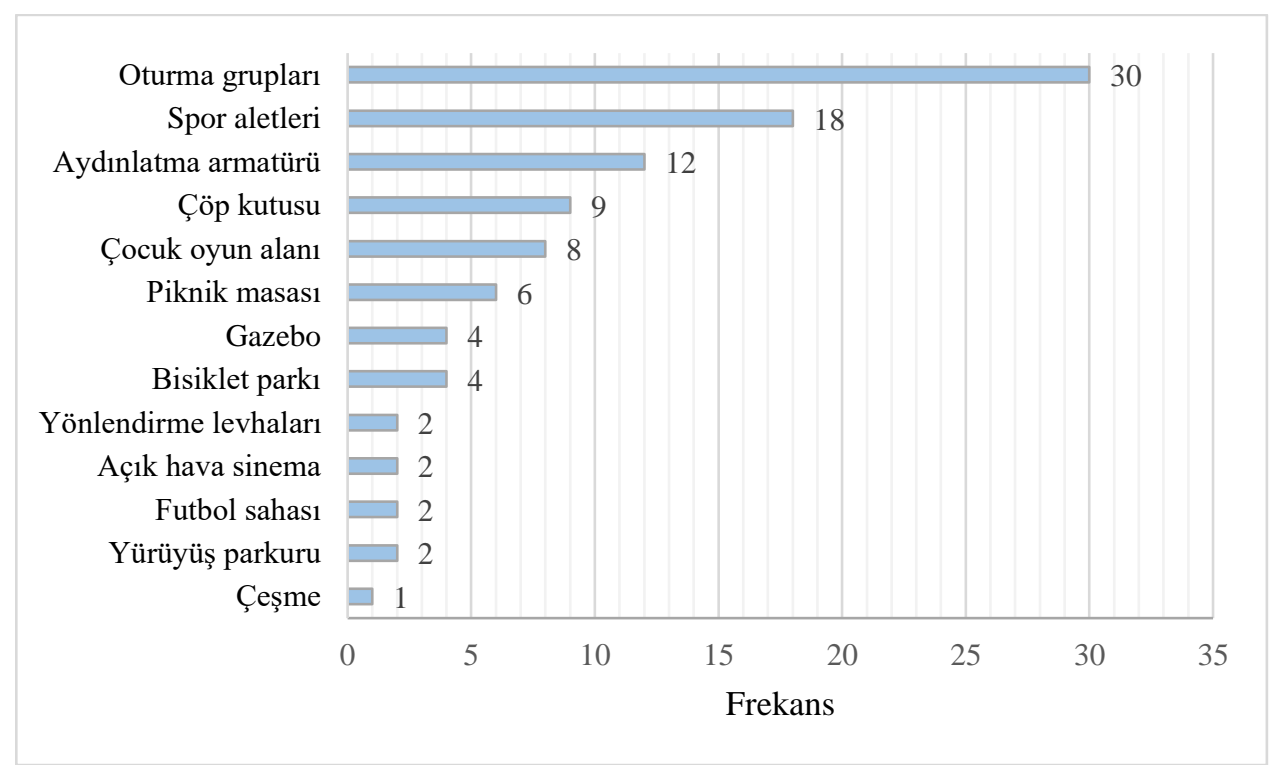

Şekil 8. Katılımcıların mahallelerindeki parklarda olmasını istedikleri donatılar.

\section{Sonuç ve Öneriler}

Katılımcıların parkları en çok ziyaret etme sebepleri, parkları kullanım amaçları, mahallerindeki parklarda gördükleri eksiklikler ile talep ettikleri donatılar konularında elde edilen bulgular bir bütün olarak 
düşünüldüğünde, katılımcıların parkları en çok arkadaşlarla zaman geçirmek, dinlenmek ve hava almak amaçlarıyla ziyaret etme sebeplerinin özellikle mahallelerindeki parklarda işaret ettikleri eksikliklerden kaynaklandığı sonucuna ulaşılabilir. Örneğin, katılımcılar mahallelerindeki parklarda bisiklet parkı, çocuk oyun alanı, futbol sahası ve çay ocağı gibi mekanların eksikliğini belirtmişlerdir. Bu tip mekanlara mahalle parklarında yer verilmesi hem parkın işlevselliğini artıracaktır hem de katılımcıların parkları daha fazla amaçlarla ziyaret etmelerinin önü açılacaktır.

Ayrıca, katılımcılar mahallelerindeki parklarda spor aletleri ve yürüyüş parkurlarını da talep etmektedir. Bu da aslında katılımcıların vücut sağlıklarına önem verdiğini ve parklarda yürümek ve spor aletlerini kullanmak istediklerini göstermektedir. Parkların planlama ve tasarımlarında halkın sağlı̆̆ına katkı yapacak aktivite alanları ve donatıları ihmal edilmemelidir. Katılımcılar mahalle parklarında sokak hayvanları için besleme kapları ile çeşme donatılarının da olmasını istemektedirler. Özellikle çocuk oyun alanı içeren parkların planlamasında hijyenin sağlanması açısından çeşme donatısına mutlaka yer verilmelidir.

Bu çalışmada katılımcılar tarafından her ne kadar belirtilmemiş olsa da, parkların engelli bireylerin kullanımı açısından da iyileştirilmesi son derece önemlidir. Bu açıdan, ileriki çalışmalarda Burdur kenti parklarının engelli bireyler için hem nitelik hem de nicelik olarak yeterliliklerinin ortaya konulması park planlama çalışmalarına büyük katkı sağlayacaktır.

Çalışmada katılımcılar mahallelerindeki parkların güvenlik, donatı elemanı, oyun alanı, bakım, spor alanı ve aydınlatma yeterliliklerini orta düzeyde bulmuşlardır. Bu sonuç, kent insanının mahalle parklarından yeterince tatmin olmadığı sonucunu ortaya çıkarmaktadır. Bu husus, ilgili kurumlar tarafından detaylı şekilde ele alınmalı ve söz konusu tatminsizliğin giderilmesi için çalışmalara hız verilmelidir.

\section{Kaynaklar}

1. Anonim. (2019). 2019 yılı Burdur park yerleri ve alanları. Burdur Belediyesi Fen İşleri Müdürlüğü, Burdur.

2. Bilgili, B.C., Çı̆̆, A., Şahin, K. (2011). Van kenti kamusal yeşil alanlarının yeterliliğinin ulaşılabilirlik yönünden değerlendirilmesi. Yüzüncü Yll Üniversitesi Tarım Bilimleri Dergisi, 21(2), 98-103.

3. Cohen, D.A., Han, B., Derose, K.P., Williamson, S., Marsh, T., Raaen, L., McKenzie, T.L. (2016). The paradox of parks in low-income areas: park use and perceived threats. Environment and Behavior, 48(1), 230-245.

4. Ellis, D., Schwartz, R. (2016). The roles of an urban parks system. https://worldurbanparks.org/images/Documents/The-Roles-of-an-Urban-Parks-System.pdf (Erişim Tarihi: 20.03.2021).

5. Erdoğan, R., Kaya, M., Olgun, R. (2020). Parklardaki çocuk oyun alanlarının kullanıcı görüşleri doğrultusunda değerlendirilmesi: Sivas kenti örneği. International Journal of Human Sciences, 17(1), 117130.

6. Galecic, N., Tomicevic-Dubljevic, J., Ocokoljic, M., Vujicic, D., Skocajic, D. (2016). Quality and utilization potential of urban parks: case study Tasmajdan park, Belgrade, Serbia. Sumarski List, 910(2016), 493-501.

7. Gökyer, E., Bilgili, B.C. (2014). Bartın ili örneğinde yeşil alanların ulaşılabilirliğinin değerlendirilmesi üzerine bir araştırma. Süleyman Demirel Üniversitesi Orman Fakültesi Dergisi, 15, 140-147.

8. Gürbüz, H., Yılmaz, V. (2017). Eskişehir rekreasyon alanlarından Kentpark'ın kullanım tercihini etkileyen faktörlerin araştırılması. Researcher: Social Science Studies, 5(9), 187-200.

9. Karadeniz, Z. (2019). Peyzaj tasarım kriterleri açısından Samsun kent parklarının incelenmesi. Yüksek Lisans Tezi (Yayımlanmamış), Ordu Üniversitesi Fen Bilimleri Enstitüsü Peyzaj Mimarlığı Anabilim Dalı, Ordu, $138 \mathrm{~s}$.

10. Kasap, S., Kara, B. (2020). Kentsel kamusal mekanların kullanılabilirliği üzerine bir araştırma: AydınTataristan Bugulma Park1, Türkiye. Adnan Menderes Üniversitesi Ziraat Fakültesi Dergisi, 17(2), $227-233$.

11. Kaya, L.G., Yücedă̆, C., Aşıkkutlu, H.S., Şeker, E. (2019). Antalya kentinde Dokuma Park1 elemanlarının kullanıcılar tarafından değerlendirilmesi. $4^{\text {th }}$ European Conference on Science, Art Culture, 43-50, 18-21 Nisan 2019, Antalya.

12. Kından, A., Çiçek, N. (2020). Samsun ili Batı Parkı'nın peyzaj özelliklerinin değerlendirilmesi. Adnan Menderes Üniversitesi Ziraat Fakültesi Dergisi, 17(2), 159-164.

13. Kiziroğlu, A.M. (2017). Türkiye'nin nüfus değişimine göre il bazında kentleşmesine bir bakış (1965-2014). Karadeniz Sosyal Bilimler Dergisi, 9(16), 153-183.

14. Kutay Karaçor, E., Çıracı, H. (2016). Farklı sosyo-ekonomik yapılara göre kamusal mekan kullanımının değerlendirilmesi. Online Journal of Art and Design, 4(4), 27-46. 
15. Mutiara, S., Isami, K. (2012). Characteristic of public small park usage in Asia Pacific countries: case study in Jakarta and Yokohama city. Procedia - Social and Behavioral Sciences, 35, 412-419.

16. Nam, J., Kim, H. (2016). Studies on usage patterns and use range of neighborhood parks: focused on 'Regional Area Parks' in Seoul, Korea, Journal of Asian Architecture and Building Engineering, 15, 495501.

17. Olgun, R., Yılmaz, T. (2018). Parkların erişilebilirlikleri üzerine bir araştırma: Niğde Kızılelma Parkı örneği, Artvin Çoruh Üniversitesi Orman Fakültesi Dergisi, 15(1), 48-63.

18. Olgun, R., Yılmaz, T. (2018). Parkların bitkisel tasarımında yenilebilir türlerin kullanımı üzerine kullanıcı görüşlerinin Antalya-Konyaaltı örneğinde araştırılması. Türkiye Peyzaj Araştırmaları Dergisi, 1(1), 42-48.

19. Önal, S., Sağır, M. (2018). Ankara kent parklarının kullanımının belirlenmesi. Ankara Araştırmaları Dergisi, 6(1), 77-90.

20. Özdemir, A. (2009). Katılımcı kimliğin oluşumunda kamusal yeşil alanların rolü: Ankara kent parkları örneği. Süleyman Demirel Üniversitesi Orman Fakültesi Dergisi, Seri: A, Sayı: 1, 144-153.

21. Polat, A.T. (2012). Kent parklarında görsel kalite ve doğallık derecesi arasındaki ilişkilerin belirlenmesi. Iğdır Üniversitesi Fen Bilimleri Enstitüsü Dergisi, 2(3), 85-92.

22. Sarı, D. (2019). İhtiyaç-etkinlik-mekan ilişkisinin kent parkları örneğinde irdelenmesi. Artvin Çoruh Üniversitesi Orman Fakültesi Dergisi, 20(2), 181-192.

23. Soydan, O., Benliay, A., Akbulut, A. (2019). Kent parklarındaki kullanım alanlarının estetik ve fonksiyonel özelliklerinin kullanıcı görüşleri doğrultusunda irdelenmesi “Antalya Muratpaşa Prof. Dr. Erdal İnönü Kent Park1 Örneği”. İn̈nü Üniversitesi Sanat ve Tasarım Dergisi, 9, 107-128.

24. Soydan, O. (2020). Kent parklarının kullanıcı memnuniyetinin Niğde örneğinde incelenmesi. Avrupa Bilim ve Teknoloji Dergisi, 20, 712-722.

25. Şenkaya, Ü., Özdemir, Y., Özdemir, Ş. (2019). Parkların erişilebilirlikleri üzerine bir araştırma: Fındıkzade Çukurbostan yaşam parkı örneği. İstanbul Sabahattin Zaim Üniversitesi Fen Bilimleri Enstitüsü Dergisi, 1(Özel Sayı 1), 53-57.

26. TÜİK. (2020). https://tuikweb.tuik.gov.tr/PreTablo.do?alt_id=1059 (Erişim Tarihi: 10.12.2020).

27. Ulu Akşit, A., Yücedağ, C., Kaya, L.G., Aşıkkutlu, H.S. (2020). Burdur kenti açık-yeşil alan potansiyelinin belirlenmesi. Artvin Çoruh Üniversitesi Orman Fakültesi Dergisi, 21(2), 284-291.

28. Yazici, K., Temizel, S. (2020). Kentsel peyzaj tasarımlarında aydınlatma donatı elemanlarının kullanımı; Yozgat Spor Vadisi Örneği. Ispec Tarım Bilimleri Dergisi, 4(4), 952-971.

29. Yazıcıoğlu, Y., Erdoğan, S. (2007). SPSS uygulamalı bilimsel araştırma yöntemleri. Detay Yayıncılık, 2. Bask1, Ankara, $335 \mathrm{~s}$.

30. Yılmaz, T., Şavklı, F., Olgun, R., Özdamarlar, E. (2014). Aydınlatmanın park kullanım tercihlerine etkileri. Inönü Üniversitesi Sanat ve Tasarım Dergisi, 4(9), 15-20.

31. Yılmaz, T., Şavklı, F., Durdu, S., Gorgulu, B. (2016a). Evaluation of fitness equipment in parks: case of Antalya city. The Pharmaceutical and Chemical Journal, 3(2),105-110.

32. Yılmaz, T., Olgun, R., Şavklı, F. (2016b). A study on park usage preferences of the elderly people. Inönü Üniversitesi Sanat ve Tasarım Dergisi, 6(14), 1-10.

33. Yücedağ, C., Kaya, L.G., Aşıkkutlu, H.S. (2018). A study on usage of urban parks: case of PamukkaleDenizli, Turkey. The International Conference on Engineering and Natural Sciences (ICENS), 78-82, 2-6 Mayıs 2018, Kiev, Ukrayna.

34. Zhu, J., Lu, H., Zheng, T., Rong, Y., Wang, C., Zhang, W., Yan, Y., Tang, L. (2020). Vitality of urban parks and its influencing factors from the perspective of recreational service supply, demand, and spatial links. International Journal of Environmental Research and Public Health, 17, 1615; doi:10.3390/ijerph17051615. 